\title{
Age-related microbiological changes in the salivary and plaque microflora of healthy adults
}

\author{
R. S. PERCIVAL, S. J. CHALLACOMBE and P. D. MARSH* \\ Department of Oral Medicine and Pathology, UMDS, Guy's Hospital, London SE1 9RT and *Pathology Division, PHLS \\ Centre for Applied Microbiology and Research, Porton Down, Salisbury SP4 QUG
}

\begin{abstract}
Summary. The effect of age on quantitative or qualitative differences in selected bacteria of dental significance and on the carriage of opportunistic pathogens and transient oral species was determined in 79 healthy, non-denture wearing individuals divided into four age groups: 20-39 years (group A), 40-59 years (group B), 60-79 years (group C) and $\geq 80$ years (group D). Samples of dental plaque and whole saliva were cultured on appropriate selective and non-selective bacteriological media. The total numbers of viable bacteria in saliva, and the prevalence of mutans streptococci in plaque and saliva were similar in all age groups. Similarly, there was no correlation between the numbers of spirochaetes in plaque and age. In contrast, statistically significantly higher mean proportions $(p=0.004)$, mean $\log _{10}$ viable counts $(p=0.001)$ and isolation frequencies $(p<0.01)$ of lactobacilli were found in the saliva of those aged $\geq 70$ years compared to subjects in group $A$. The isolation frequency $(p<0.05)$ and proportions $(p=0.056)$ of staphylococci in saliva were also higher in those aged $\geq 70$ years. Yeasts were isolated most often and in higher numbers from saliva in those aged $\geq 80$ years and the proportion of yeasts was higher after 60 years of age, but these differences were not significant in comparison with results from individuals in group A. Actinomyces spp. were commonly isolated from plaque, but there was a change, with age, in the ratio of the proportions of $\boldsymbol{A}$. viscosus and $\boldsymbol{A}$. naeslundii so that $\boldsymbol{A}$. viscosus predominated in elderly subjects (groups $\mathrm{C}$ and $\mathrm{D}$ ). The results suggest that genuine age-related changes in the oral microflora can be detected, particularly after the age of 70 years, which are not related to denture-wearing or disease.
\end{abstract}

\section{Introduction}

The oral cavity comprises a series of different environments such as the tongue, cheek, palate, tooth surfaces and gingival crevice, which are colonised by different microfloras. These microfloras are influenced by host factors such as tooth eruption or loss of teeth, oral hygiene, and hormonal changes of the host. ${ }^{1}$ The numbers and types of micro-organisms in the mouth also change with age, particularly in the early years during the development of the dentition. ${ }^{2,3}$ Similarly, the isolation frequency of black-pigmented gramnegative anaerobic bacilli, ${ }^{4,5}$ spirochaetes, ${ }^{6-8}$ and Actinomyces viscosus ${ }^{9}$ are reported to increase in adolescents and young adults. However, much less is known of the effect of subsequent natural ageing processes on the stability of the resident oral microflora.

The host is able to maintain microbial homeostasis in the mouth by means of specific and innate host defences. ${ }^{10}$ These defences, together with the commensal microflora, act to prevent colonisation by nonresident species and opportunist pathogens. Cell-

Received 30 May 1990; revised version accepted 8 Oct. 1990. mediated immunity is reported to decline with age, ${ }^{11}$ but little is known about the effect of age on the oral host defences, ${ }^{12}$ nor how this may be reflected in changes in the oral microflora. Thus, the aim of the present study was to compare the resident oral microflora of healthy subjects in different age groups. Because of the complexity of the microflora and the known inter-subject variation, only selected species of dental significance were chosen for comparison, together with species considered normally to be present only transiently, thereby acting as indicators of the breakdown of homeostasis. ${ }^{10}$

\section{Materials and methods}

\section{Study population}

A total of 79 healthy subjects took part in the study. They were sub-divided into four groups: (A) 20-39 years, mean age 26.8 years, $æ 1.03, \mathrm{n}=30$; (B) $40-59$ years, mean age $50 \cdot 1$ years, $æ 1 \cdot 1, n=23$; (C) $60-79$ years, mean age 72.5 years, $æ 1 \cdot 4, n=16$; and (D) $\geq$ 80 years, mean age 83.8 years, $æ 0.9, n=10$. The subjects in groups A and B included staff and patients 
of Guy's Hospital, London, who were attending routine dental examinations, and groups $C$ and $D$ were elderly groups living mainly in sheltered residential accommodation comprising a mixture of houses, apartments and units with access to central dining facilities (Morden College, London). The study population satisfied the following requirements for inclusion within this project: (a) the presence of a minimum number of teeth (seven), including one molar; (b) the absence of active oral disease; (c) the absence of dentures; (d) no recent history of antimicrobial therapy or other drug therapy, including immunosuppressives; and (e) no history of diabetes. A haematological screen was performed on all subjects in groups $C$ and D to exclude latent disease. These subjects also received regular medical checks.

\section{Collection of saliva samples}

Unstimulated whole saliva was collected from all subjects by direct expectoration into a sterile container during a 10-min period.

\section{Collection of plaque samples}

Supragingival molar plaque was collected above the gingiva on the lower right or left sixth tooth by running a standard dental probe along the buccal and mesiobuccal surfaces. Plaque samples were transferred into $1 \mathrm{ml}$ of reduced transport fluid ${ }^{13}$ in sterile bottles containing 20-30 glass beads (3-mm diameter; Jencons Scientific Ltd, Bedfordshire). Both unstimulated whole saliva and plaque samples were processed within 2$4 \mathrm{~h}$ of collection.

\section{Microbiological procedures}

Saliva samples were dispersed by vortex mixing for $30 \mathrm{~s}$ and 10-fold dilutions were prepared in reduced transport fluid. ${ }^{13}$ Samples of $100 \mu$ at dilutions from $10^{3}$ to $10^{7}$ were plated in duplicate on to Columbia blood agar and incubated aerobically and anaerobically in an atmosphere of $\mathrm{CO}_{2} 10 \%$ in $\mathrm{H}_{2}$ at $37^{\circ} \mathrm{C}$ for 4 days, to determine the total numbers of aerobic and anaerobic $\mathrm{cfu}$. The saliva samples from neat to a dilution of $10^{4}$ were also plated on to a range of selective media to enable key micro-organisms to be enumerated. The media were Sabouraud Agar (Oxoid) for Candida spp., MacConkey Agar (Oxoid) for enteric bacteria, Rogosa Agar(Oxoid) for Lactobacillus spp., Mannitol-Salt Agar (Oxoid) for Staphylococcus spp. and TYC medium (Lab M, Bury) with sucrose $20 \% \mathrm{w} / \mathrm{v}$ and bacitracin $0 \cdot 1$ units $/ \mathrm{ml}^{14}$ (TYCSB) for mutans streptococci. Sabouraud, MacConkey, and Mannitol-Salt media were incubated aerobically at $37^{\circ} \mathrm{C}$ for 4 days, TYCSB medium was incubated anaerobically at $37^{\circ} \mathrm{C}$ for 4 days, and Rogosa medium was incubated in $\mathrm{CO}_{2} 5-10 \%$ in air at $37^{\circ} \mathrm{C}$ for 4 days.

Plaque samples were held under $\mathrm{CO}_{2}$ and dispersed by vortex mixing for $1 \mathrm{~min}$ with $3-\mathrm{mm}$ glass beads to disaggregate any clumps of micro-organisms within the plaque. Plaque samples were treated in the same way as saliva samples except that, in addition to the above media, samples were plated on CFAT medium, ${ }^{15}$ which is selective for $A$. viscosus and $A$. naeslundii, and incubated anaerobically at $37^{\circ} \mathrm{C}$ for up to 10 days. Facultatively anaerobic, catalase-positive and catalase-negative isolates were identified as presumptive $A$. viscosus and $A$. naeslundii, respectively. Plaque samples were also plated on Columbia blood agar supplemented with vancomycin $2.5 \mu \mathrm{g} / \mathrm{ml}$ and incubated anaerobically at $37^{\circ} \mathrm{C}$ for up to 21 days for the isolation of black-pigmented gram-negative anaerobic bacilli. Yeasts were identified with API 20C commercial galleries (API, Basingstoke) according to the manufacturer's instructions. Coagulase-positive colonies on Mannitol-Salt agar were considered to be $S$. aureus.

Dark field microscopy was used to determine the presence and numbers of spirochaetes in dispersed plaque samples. ${ }^{16}$ For each sample, 60 fields were viewed and the number of spirochaetes in each counted and summated. Results were expressed as a percentage of the viable count.

The reproducibility of the bacterial isolation techniques was tested in six volunteers by dividing the saliva samples in two. Subsequently, these were treated as separate samples and serially diluted; inocula were spread on duplicate plates of Columbia blood agar and selective media for yeasts, enteric bacteria, lactobacilli, staphylococci and mutans streptococci.

\section{Statistical procedures}

Viable counts were transformed to $\log _{10} \mathrm{cfu}$; results are presented as the mean of the $\log _{10} \mathrm{cfu}$, and were compared by analysis of variance and Student's $t$ test. Isolation frequencies were compared by $\chi^{2}$ test, with Yates's correction for small numbers where appropriate. Spearman rank correlations were performed on the whole study population to determine significant correlations between age and percentage viable counts and age and $\log _{10}$ viable counts. Where data were to be log-transformed, and micro-organisms were not detected, the baseline was set as half of the minimum levels of detection. The latter were $10 \mathrm{cfu} / \mathrm{ml}$ of saliva or plaque sample for yeasts, lactobacilli and staphylococci, and $10^{3} \mathrm{cfu}$ per sample for mutans and total streptococci or total $\mathrm{cfu}$. This represented a detection sensitivity of about 1 in $10^{8} \mathrm{cfu}$.

\section{Results}

The mean haemoglobin concentrations of subjects in groups $\mathrm{C}$ and $\mathrm{D}$ were within the normal range and were not significantly different from those in the younger age groups, implying no latent disease in the elderly.

The mean variation in cfu (percentage varia- 
Table I. Frequencies of isolation of selected micro-organisms from saliva (S) or plaque (P) as a function of age

\begin{tabular}{|c|c|c|c|c|c|c|c|c|}
\hline \multirow{3}{*}{ Micro-organism } & \multicolumn{8}{|c|}{ Percentage isolation frequency from group } \\
\hline & \multicolumn{2}{|c|}{$A(n=30)$} & \multicolumn{2}{|c|}{$B(n=23)$} & \multicolumn{2}{|c|}{$C(n=16)$} & \multicolumn{2}{|c|}{$\mathrm{D}(\mathrm{n}=10)$} \\
\hline & $\mathbf{S}$ & $\mathbf{P}$ & $\mathbf{S}$ & $\mathbf{P}$ & $\mathbf{S}$ & $\mathbf{P}$ & $\mathbf{S}$ & $\mathbf{P}$ \\
\hline Spirochaetes & & 43 & & 30 & & 44 & & 50 \\
\hline Enterobacteria & 0 & 0 & 0 & 0 & 0 & 0 & 0 & $\mathbf{0}$ \\
\hline Lactobacilli & 30 & 10 & 43 & 9 & 81 & 13 & 60 & 0 \\
\hline Staphylococci & 60 & 17 & 61 & 4 & 88 & 19 & 70 & 10 \\
\hline BPGNAB & . & 17 & $\ldots$ & 4 & $\ldots$ & 6 & $\ldots$ & 10 \\
\hline $\begin{array}{l}\text { Mutans } \\
\text { streptococci }\end{array}$ & & & & & & & & \\
\hline streptococci & 77 & 40 & 74 & 52 & 88 & 63 & 60 & 50 \\
\hline A. viscosus & & 23 & $\ldots$ & 17 & $\ldots$ & 44 & $\ldots$ & 30 \\
\hline A. naeslundii & & 50 & & 65 & $\ldots$ & 31 & $\ldots$ & 60 \\
\hline Yeasts & 23 & 10 & 39 & 22 & 19 & 6 & 50 & 30 \\
\hline
\end{tabular}

$A, 20-39$ years; $B, 40-59$ years; $C, 60-79$ years; $D, \geq 80$ years. BPGNAB, black pigmented gram-negative anaerobic bacilli. ..., not measured.

tion $=$ difference $\times 100 /$ mean) between the total viable counts on duplicate agar plates of each saliva sample was $16.2 \%$; the variation between repeat samples was $17 \cdot 4 \%$. The similarity between the duplicate and the replicate samples demonstrated satisfactory reproducibility in the techniques employed.

There were no significant differences in the total number of viable cells $(\mathrm{cfu} / \mathrm{ml})$ in saliva samples from individuals in the four age groups, although the lowest mean count was in those aged $\geq 80$ years. The mean viable counts for age groups $A, B, C$ and D were $9 \cdot 22$, $9 \cdot 52,9 \cdot 51$ and $8.60 \log _{10} \mathrm{cfu} / \mathrm{ml}$. In contrast, statistically significant differences were found in the prevalence of certain groups of micro-organism in saliva. The isolation frequency (table I), mean $\log _{10}$ viable counts (table II) and proportions (fig. 1) of lactobacilli in saliva were significantly higher $(p=0.01, p=0.002$, $p=0.006$, respectively) in those aged $\geq 60$ years (groups C and D) than in group A. Subdivision of group $C$ into persons aged 60-69 years (group $C_{1}$ ) or 70-79 years (group $C_{2}$ ) revealed that these increases occurred mainly in those aged $\geq 70$ years $(p=0.01$, $\mathrm{p}=0.001, \mathrm{p}=0.004$, respectively). In the series as a whole there was a significant correlation between age and the presence of lactobacilli, expressed as either $\log _{10}$ cfu or percentage viable count (table IV).

The isolation frequency of staphylococci from saliva

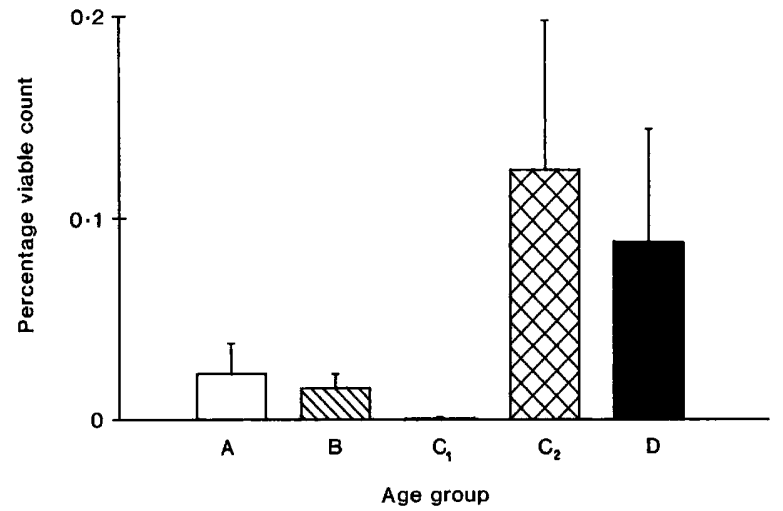

Fig. 1. Comparison of the mean percentage viable count (bar, SEM) of lactobacilli in saliva in each age group. A, 20-39 years; B, 40-59 years; $C, 60-79$ years; $D, \geq 80$ years. Group $C$ was subdivided into those aged 60-69 years $\left(C_{1}\right)$, and those aged $70-79$ years $\left(C_{2}\right)$.

was also significantly higher $(\mathrm{p}<0.05)$ from those in groups $\mathrm{C}$ and $\mathrm{D}$ (table I) than from group $\mathrm{A}$; again the increases occurred primarily in those aged $\geq 70$ years $(p<0.05)$. The mean $\log _{10}$ viable count (table II) and proportions (fig. 2) of staphylococci were highest in groups $\mathrm{C}$ and $\mathrm{D}$, and in group $\mathrm{D}$, respectively, although these findings were not significantly different from those in group A. The higher proportions of staphylococci in saliva of those aged $\geq 70$ years did, however, approach statistical significance $(\mathrm{p}<0.056)$. A mean of $49 \%$ of all staphylococcal isolates were coagulase positive and this proportion was similar in each age group. The isolation frequency (table I) and mean viable counts (table II) of yeasts in saliva were highest in those aged $\geq 80$ years, and their proportions were higher in those aged $\geq 60$ years (fig. 3 ), but these findings were not statistically significantly different from those in group A, mainly because of the large variation in counts between individuals. The majority of yeasts were identified as Candida albicans and this species was isolated from $19(24 \%)$ of 79 subjects; 4 $(5 \%)$ of 79 subjects had $C$. tropicalis and $3(4 \%)$ of 79 subjects had $C$. parapsilosis. There was no discernible trend in the prevalence of mutans streptococci in saliva, although the highest proportions were found in those aged $\geq 80$ years (group D) (fig. $4 \mathrm{a}$ ). In $10(13 \%$ ) of 79 subjects salivary counts of mutans streptococci were $>10^{6} \mathrm{cfu} / \mathrm{ml}$. No enteric bacteria were isolated from the saliva of any subject (table I).

There were no clear age-related trends in the

Table II. Viable counts of selected micro-organisms in saliva as a function of age

\begin{tabular}{|c|c|c|c|c|}
\hline \multirow{2}{*}{ Micro-organism } & \multicolumn{4}{|c|}{ Mean $\log _{10}(\mathrm{SEM})$ viable count from group } \\
\hline & $A(\mathbf{n}=30)$ & $B(n=23)$ & $C(n=16)$ & $D(n=10)$ \\
\hline $\begin{array}{l}\text { Lactobacilli* } \\
\text { Staphylococci } \dagger \\
\text { Mutans streptococci } \ddagger \\
\text { Yeasts } \ddagger\end{array}$ & $\begin{array}{l}1.76(0.30) \\
2 \cdot 71(0.34) \\
4.48(0.20) \\
1.40(0.24)\end{array}$ & $\begin{array}{l}1.68(0.33) \\
2.28(0.33) \\
4.67(0.30) \\
1.56(0.26)\end{array}$ & $\begin{array}{l}3.67(0.43) \\
3.43(0.31) \\
4.92(0.30) \\
1.40(0.38)\end{array}$ & $\begin{array}{l}3.25(0.72) \\
3.46(0.47) \\
4.45(0.52) \\
2.40(0.59)\end{array}$ \\
\hline
\end{tabular}

${ }^{*}$ Group A vs D, NS (p=0.06); group A vs C, $\mathrm{p}=<0.001$.

† Group B vs $\mathrm{C}, \mathrm{p}=<0.02$; group $\mathrm{B} v s \mathrm{D}, \mathrm{p}=<0.05$.

$\ddagger$ No significant differences. 
Table III. Viable counts of selected micro-organisms in dental plaque as a function of age

\begin{tabular}{l|llll}
\hline \multirow{2}{*}{\multicolumn{1}{c|}{ Micro-organism }} & \multicolumn{4}{c}{ Mean percentage count (SEM) in group } \\
\cline { 2 - 5 } & $\mathrm{A}(\mathrm{n}=30)$ & $\mathrm{B}(\mathrm{n}=23)$ & $\mathrm{C}(\mathrm{n}=16)$ & $\mathrm{D}(\mathrm{n}=10)$ \\
\hline Lactobacilli & & & & \\
Staphylococci & $0.01(0.01)$ & $2.51(2.50)$ & $0.003(0.001)$ & 0 \\
Yeasts & $0.75(0.47)$ & 0 & $0.06(0.03)$ & 0.001 \\
Spirochaetes $\left(\times 10^{6}\right)$ & $0.43(1.55)$ & $0.07(0.05)$ & 0.01 & $0 \cdot 18(0 \cdot 13)$ \\
& $142(97)$ & $180(165)$ & $42(27)$ & $10.9(8.6)$ \\
\hline
\end{tabular}

isolation frequency (table I) or proportions (table III) of yeasts, lactobacilli or staphylococci from dental plaque. The cell counts of spirochaetes appeared to decrease with age on a group basis (table III) but this was not statistically significant. However, on an individual basis in the whole series, there was a significant negative correlation between age and $\log _{10}$ percentage viable count $(r=-0.245, n=79, p<0.05)$, although there was no obvious correlation between spirochaetes and the gingival index at the sample site or in the mouth as a whole. Black-pigmented gramnegative anaerobic bacilli were isolated infrequently (but more often from group A; table I) and in low numbers from dental plaque, irrespective of age. No enteric bacteria were isolated from plaque samples (table I). In contrast, Actinomyces spp. were commonly detected in plaque; the majority of isolates resembled $A$. viscosus and $A$. naeslundii (table I). In the younger

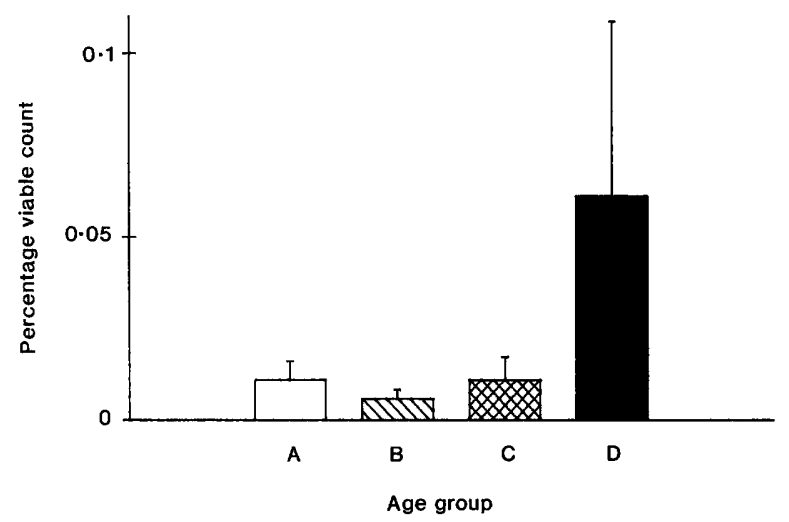

Fig. 2. Comparison of the mean percentage viable count (bar, SEM) of staphylococci in saliva in the four age groups.

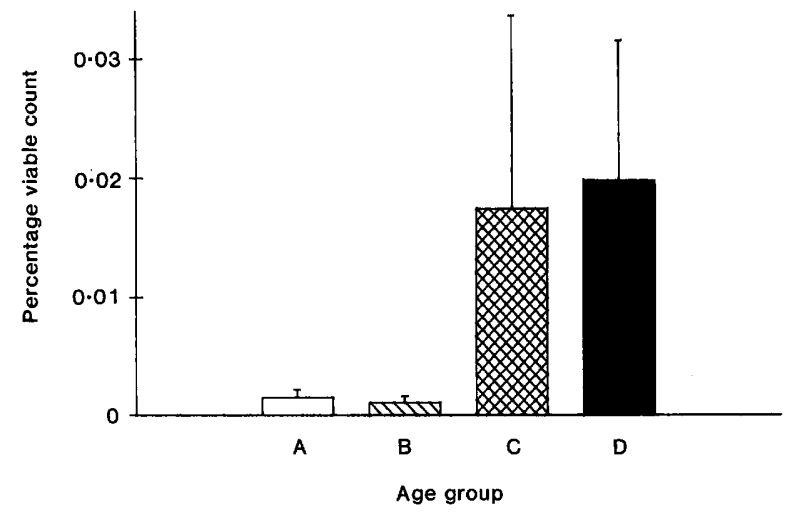

Fig. 3. Comparison of the mean percentage viable count (bar, SEM) of yeasts in saliva in the four age groups. age groups (A and B), A. naeslundii was in the highest proportions whereas the situation was reversed in those aged $\geq 60$ years, in whom $A$. viscosus predominated (fig. 5). The ratios of $A$. viscosus to $A$. naeslundii in age groups A, B, C and D were 0.76, 0.25, 2.04 and $2 \cdot 46$, respectively. There were also lower proportions of mutans streptococci in plaque from the most elderly subjects, but this trend was not statistically significant (fig. 4b).

\section{Discussion}

There is little information about the effect of natural ageing processes on the stability of the resident human microflora. Such information could be of value to determine the treatment needs for this increasing sector of the population, and may identify individuals at risk of certain infections.

There are several problems in the design of studies which attempt to correlate changes in the microflora with age. These include lack of a universally accepted definition of any age group; clearly, the chronological age of a person does not necessarily equate with their "physiological" age. Similarly, individuals in population groups generally have to satisfy certain minimum requirements for inclusion in a study. These may relate to the presence of a certain number of teeth, the absence of dentures or of active disease, or no recent history of medical treatment. Such requirements may be met easily by most of those in the younger age groups but a study population which involves the elderly may be skewed by the inclusion of a disproportionate number of so-defined "healthy" individuals

Table IV. Correlation between age and percentage viable count and $\log _{10}$ viable count

\begin{tabular}{l|cc}
\hline \multirow{2}{*}{ Correlation } & \multicolumn{2}{|c}{$\begin{array}{c}\text { Spearman rank correlation } \\
\text { (Z value) with }\end{array}$} \\
\cline { 2 - 3 } & $\begin{array}{c}\text { percentage viable } \\
\text { count }\end{array}$ & $\begin{array}{c}\log _{10} \text { viable } \\
\text { count }\end{array}$ \\
\hline Age $v$ seast & 0.352 & 0.971 \\
Age $v$ s lactobacilli & $1.968^{*}$ & $3 \cdot 182 \dagger$ \\
Age $v$ staphylococci & 0.428 & 0.733 \\
Age $v$ s mutans streptococci & 0.899 & $1 \cdot 212$ \\
\hline${ }^{*} \mathrm{p}=0.05$. & & \\
$\dagger \mathrm{p}=0.002$. & & \\
\hline
\end{tabular}



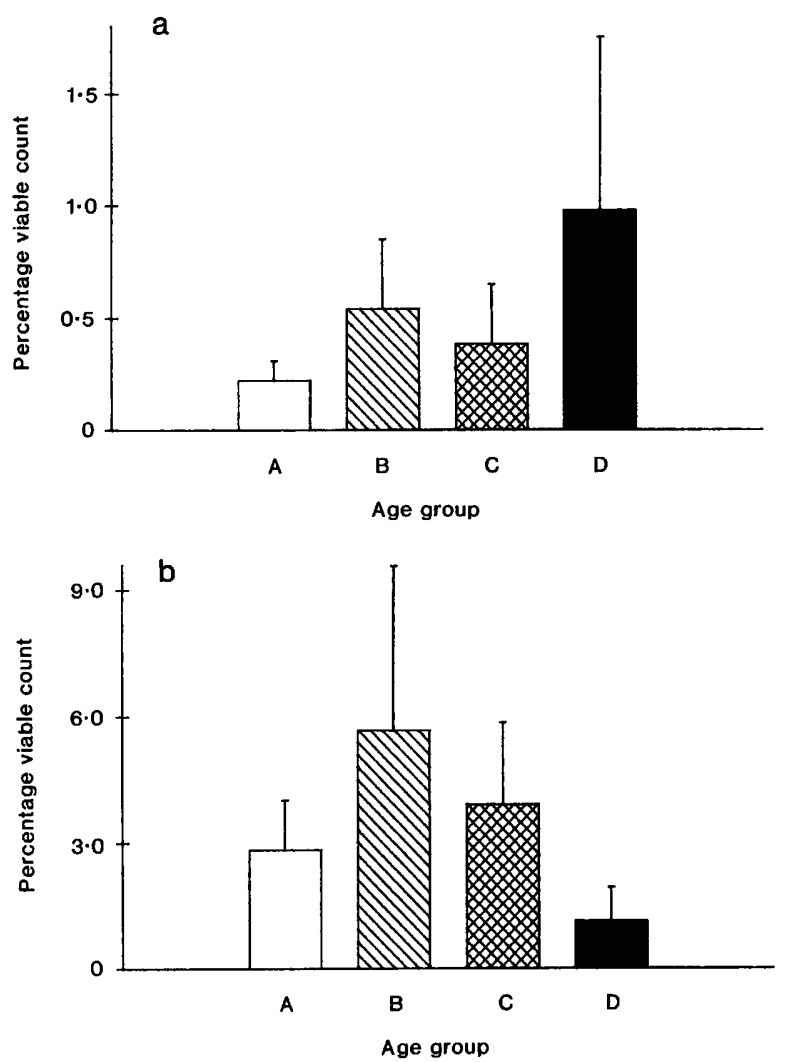

Fig. 4. Comparison of the mean percentage viable count of mutans streptococci (bar, SEM) in (a) saliva, and (b) plaque in the four age groups.

who are regarded as "normal" but may not be representative of the elderly. Finally, even if quantitative differences in the microflora do occur with age, the known wide inter-site and inter-subject variations can make it difficult to establish these changes in a cross-sectional survey. Our inclusion of only healthy individuals, even in the most elderly age groups, was intended to prevent any confusion with changes in the oral microflora which might be due to disease or to any indirect age-associated factors, such as medication or denture-wearing, and is a unique feature of this study.

In the young, changes in the oral microflora that have been related directly to age are reasonably well

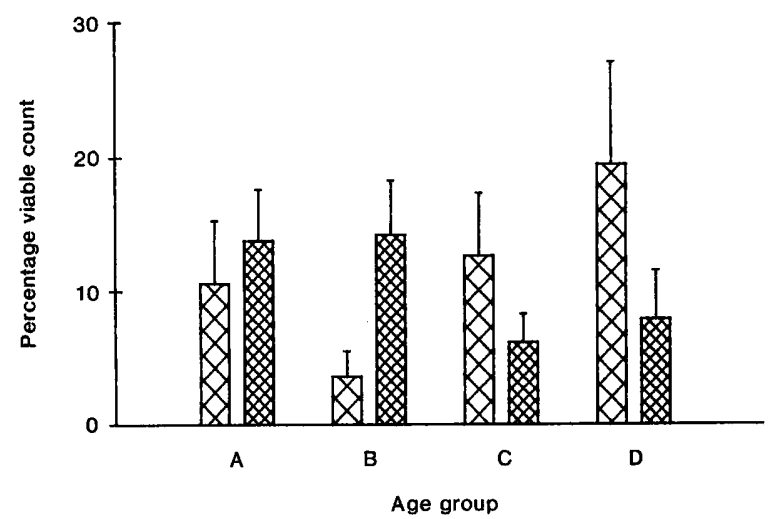

Fig. 5. Mean percentage viable count (bar, SEM) of A. viscosus ( $)$ and A. naeslundii (in dental plaque in the four age groups. established and are usually associated with major perturbations to the habitat (e.g., tooth eruption, hormonal changes, etc.). ${ }^{2-8}$ In adults, the resident microflora is believed to remain relatively stable unless the environment is disturbed, as occurs during disease, but there have been few studies of the oral microflora of healthy elderly subjects. Qualitative differences in the microbial composition of plaque between young and elderly individuals were inferred from the biochemical composition and enzyme activity of pooled samples, ${ }^{17}$ but a detailed bacteriological analysis was not reported.

The isolation frequencies of $A$. viscosus, ${ }^{9}$ blackpigmented gram-negative anaerobic bacilli ${ }^{4,5}$ and spirochaetes $^{6-8}$ are reported to increase with age in adolescents and young adults. In the present study, no significant age-associated changes in both the prevalence or proportions of spirochaetes or black-pigmented gram-negative anaerobic bacilli were found; the presence of both groups of organism appeared to be independent of gingival inflammation. Actinomyces spp. were commonly isolated, but there was a marked shift in the ratio of the predominant species associated with ageing. A. naeslundii was in the highest proportions in the younger groups (A and B) whereas this was reversed in those aged $\geq 60$ years (groups $C$ and D) in whom $A$. viscosus predominated.

There were no clear age-related differences in either the isolation frequency or in the proportions of mutans streptococci from saliva or plaque of subjects in our study; these organisms were isolated commonly and sometimes in high numbers, even in the most elderly age group. In contrast, the recovery, absolute viable counts, and proportions of lactobacilli in saliva increased with age, particularly in those aged $\geq 70$ years. A high carriage rate for cariogenic bacteria was also reported in a study of elderly Swedish individuals (mean age 85 years) ${ }^{18}$ and elderly Americans (range 60-87 years, median 68 years). ${ }^{19}$ In one of these studies, analyses revealed that lactobacilli were more prevalent in individuals wearing dentures, ${ }^{18}$ whereas our results showed higher levels of these bacteria in elderly dentate subjects proving this to be a genuine age-related observation. The combined findings from these studies suggest that those who retain natural teeth remain at risk of both enamel and root surface caries with increasing age. Many of the elderly people from these studies had $>10^{6} \mathrm{cfu}$ of mutans streptococci/ml of saliva and could also act, therefore, as vectors in the transmission of these potentially cariogenic bacteria. ${ }^{18,19}$

The prevalence of yeasts in saliva also increased with age, with greater isolation frequencies and viable counts in those aged $\geq 80$ years, and higher proportions in those aged $\geq 60$ years; although, due to the wide inter-subject variation in counts between subjects, these differences were not statistically significant. Denture-wearers were excluded from our study so that the increased prevalence of Candida spp. in the elderly was probably due to ageing and may reflect changes 
in the activity of the host defences or a decrease in saliva flow. Enhanced oral colonisation rates with yeasts have also been found following irradiation or cytotoxic therapy. Such treatments reduce saliva flow rates which might also affect IgA levels; the latter can inhibit the adhesion of candida to oral surfaces. Thus, although total IgA levels have been reported to be similar in old (70-91 years) and in young adults, the older adults had far lower levels of specific antibodies reacting with two common mucosal antigens (Str. mutans glucosyl transferase and killed poliovirus). ${ }^{20}$ Also, opsonic activity against a standard preparation of yeast cells was impaired in saliva samples from elderly subjects (mean age 72 years) compared with younger control individuals (mean age 33 years). ${ }^{21}$

Work is in progress to compare the host defences in the different age groups in our study. Preliminary results indicate a reduced whole salivary flow but not parotid salivary flow. The elderly can also suffer from various nutritional deficiencies (e.g., trace elements, vitamins) and it has been claimed that these could be predisposing factors in candidiasis, ${ }^{22,23}$ and hence to an increased carriage of yeasts.

In our study, enterobacteria were never isolated, even from the most elderly participants. Previously, although pseudomonads had been isolated from saliva, no trends with age had emerged. ${ }^{24}$ In other studies, a range of enterobacteria (e.g., Klebsiella spp., Escherichia coli, Proteus spp.) have been isolated from the oropharynx of the elderly ${ }^{25}$ but, perhaps significantly, the isolation rates for these organisms increased as the individuals became more debilitated and hospitalised. The prevalence of gram-negative bacilli among the oropharyngeal microflora was also low in another study of physiologically normal subjects but rose markedly in elderly moribund patients (mean age 60 years). ${ }^{26}$ The oral carriage of staphylococci is also low in healthy subjects but is higher in immunodeficient ${ }^{27}$ and myelosuppressed subjects, ${ }^{28,29}$ and in patients with severe Sjögren's syndrome. ${ }^{30}$ In our study, the isolation of staphylococci from saliva was significantly higher in those aged $\geq 70$ years; their proportions and viable counts in saliva were also greater in this age group. As it has been reported that cell mediated immunity declines with age, ${ }^{11}$ it is possible that homeostatic mechanisms that normally serve to maintain the balance of the resident oral microflora may become impaired in the elderly.

In summary, the isolation, viable counts and proportions of lactobacilli in saliva increased with age, as did the isolation of potential opportunist pathogens and other non-resident oral micro-organisms (yeasts and staphylococci). The ratio of the prevalence of Actinomyces spp. also shifted with age. Future work will attempt to determine the levels of the innate and specific host defences in the healthy subjects in different age groups described here, and then compare them with those of patients of a similar age but with various diseases. In certain individuals, alterations in the integrity of the host defences may perturb the stability of the resident oral microflora and lead to the increased likelihood of colonisation by potentially pathogenic species. These studies may help in the recognition of at-risk elderly subjects.

This research was generously supported by a grant from the Hayward Foundation, London. We thank Mr N. Girdler, Miss S. van Oudgaarden and Miss Y. Essani for collecting the samples, and the Trustees, staff and residents of Morden College, Blackheath, London SE3, for their help and co-operation throughout the study.

\section{References}

1. van Winkelhoff AJ, van Steenbergen TJM, de Graaff J. The role of black-pigmented Bacteroides in human oral infections. J Clin Periodontol 1988; 15: 145-155.

2. Socransky SS, Manganiello SD. The oral microbiota of man from birth to senility. J Periodontol 1971; 42: 485-496.

3. Kornman KS. Age, supragingival plaque and steroid hormones as ecological determinants of the sub-gingival flora. In: Genco RJ, Mergenhagen SE (eds) Host-parasite interactions in periodontal disease. Washington DC, American Society for Microbiology. 1982: 132-138.

4. Bailit HL, Baldwin DC, Hunt EE. The increasing prevalence of gingival Bacteroides melaninogenicus with age in children. Arch Oral Biol 1964; 9: 435-438.

5. Kelstrup J. The incidence of Bacteroides melaninogenicus in human gingival sulci, and its prevalence in the oral cavity at different stages. Periodontics 1966; 4: 14-18.

6. Socransky SS, Gibbons RJ, Dale AC, Bortnick L, Rosenthal E, MacDonald JB. The microbiota of the gingival crevice area of man. I. Total microscopic and viable counts and counts of specific organisms. Arch Oral Biol 1963; 8: 275280.

7. de Araujo WC, MacDonald JB. Gingival crevice microbiota of five preschool children. J Periodontal 1964; 35: 285-289.

8. Mikx FHM, Matee MI, Schaeken MJM. The prevalence of spirochetes in the subgingival microbiota of Tanzanian and Dutch children. J Clin Periodontol 1986; 13: 289-293.

9. Ellen RP. Establishment and distribution of Actinomyces viscosus and Actinomyces naeslundii in the human oral cavity. Infect Immun 1976; 14: 1119-1124.

10. Marsh PD. Host defenses and microbial homeostasis: role of microbial interactions. J Dent Res 1989; 68: 1567-1575.

11. Czonkowska A, Korlak J. The immune response during ageing. J Gerontol 1979; 34: 9-14.

12. Aldred MJ. Immunological changes in relation to age. Microb Ecol Hlth Dis 1988; 1: 275-277.

13. Hoover CI, Newbrun E. Survival of bacteria from human dental plaque under various transport conditions. $J$ Clin Microbiol 1977; 6: 212-218.

14. van Palenstein Helderman WH, Ijsseldijk M, Huis in't Veld JHJ. A selective medium for the two major subgroups of the bacterium Streptococcus mutans isolated from human dental plaque and saliva. Arch Oral Biol 1983; 28: 599603.

15. Zylber LJ, Jordan HV. Development of a selective medium for detection and enumeration of Actinomyces viscosus and Actinomyces naeslundii in dental plaque. J Clin Microbiol 1982; 15: 253-259.

16. Africa CW, Parker JR, Reddy J. Bacteriological studies of subgingival plaque in a periodontitis-resistant population. 1. Darkfield microscopic studies. J Periodont Res 1985; 20 : 1-7.

17. Holm-Pedersen P, Folke LEA, Gawronski TH. Composition and metabolic activity of dental plaque from healthy young and elderly individuals. J Dent Res 1980; 59: 771-776. 
18. Emilson CG, Thorselius I. Prevalence of mutans streptococci and lactobacilli in elderly Swedish individuals. Scand $J$ Dent Res 1988; 96: 14-21.

19. Fitzgerald DB, Fitzgerald RJ, Adams BO, Morhart RE. Prevalence, distribution of serotypes, and cariogenic potential in hamsters of mutans streptococci from elderly individuals. Infect Immun 1983; 41: 691-697.

20. Smith DJ, Taubman MA, Ebersole JL. Ontogeny and senescence of salivary immunity. $J$ Dent Res $1987 ; 66: 451-456$.

21. Ganguly R, Stablein J, Lockey RF, Shamblin P, Vargas L. Defective antimicrobial functions of oral secretions in the elderly. J Infect Dis 1986; 153: 163-164.

22. Challacombe SJ. Haematological abnormalities in oral lichen planus, candidiasis, leukoplakia and non-specific stomatitis. Int J Oral Maxillofac Surg 1986; 15: 72-80.

23. Samaranayake LP. Nutritional factors and oral candidosis. $J$ Oral Pathol 1986; 15: 61-65.

24. Sutter VL, Hurst V, Landucci AO. Pseudomonads in human saliva. J Dent Res 1966; 45: 1800-1803.

25. Valenti WM, Trudell RG, Bentley DW. Factors predisposing to oropharyngeal colonization with gram-negative bacilli in the aged. New Engl J Med 1978; 298: 1108-1111.

26. Tillotson JR, Finland $M$. Bacterial colonization and clinical superinfection of the respiratory tract complicating antibiotic treatment of pneumonia. J Infect Dis 1969; 119: 597-624.

27. Brown LR, Mackler BF, Levy BM et al. Comparison of the plaque microflora in immunodeficient and immunocompetent dental patients. J Dent Res 1979; 58: 2344-2353.

28. Minah GE, Rednor JL, Peterson DE, Overholser CD, Depaola LG, Suzuki JB. Oral succession of gram-negative bacilli in myelosuppressed cancer patients. J Clin Microbiol 1986; 24: $210-213$.

29. Bergmann OJ, Kilian M, Ellegaard J. Potentially pathogenic microorganisms in the oral cavity during febrile episodes in immunocompromised patients with haematologic malignancies. Scand J Infect Dis 1989; 21: 43-51.

30. MacFarlane TW. The oral ecology of patients with severe Sjögren's syndrome. Microbios 1984: 41: 99-106. 